\title{
INTERDISCIPLINARIDADE NA PRÁTICA: A EXPERIÊNCIA DA APLICAÇÃO DO SOFTWARE PREACTOR COMO FERRAMENTA DE INTEGRAÇÃO CURRICULAR NO CURSO DE GRADUAÇÃO EM ENGENHARIA DE PRODUÇÃO
}

\section{INTERDISCIPLINARITY IN PRACTICE: THE EXPERIENCE OF PREACTOR SOFTWARE AS A TOOL FOR CURRICULAR INTEGRATION INTO THE INDUSTRIAL ENGENEERING UNDERGRADUATE PROGRAM}

\author{
Patrícia Alcântara Cardoso ${ }^{1}$ \\ ${ }^{1}$ Pontifícia Universidade Católica do Paraná - PUCPR - Brasil patrícia@cardoso.com
}

\begin{abstract}
Resumo
A Engenharia de Produção é a menos tecnológica, porém a mais completa das engenharias, pois além de estudar as tecnologias básicas, relaciona-se com várias outras áreas, tais como estratégia, economia e finanças, englobando um conjunto maior de conhecimentos e habilidades. Visando integralizar as teorias ensinadas em sala de aula pelos professores do $7^{\circ}$ período do curso de graduação em Engenharia de Produção, utilizou-se o software Preactor. Os alunos são divididos em grupos e com a orientação de duas professoras, os estudos de casos são desenvolvidos durante o semestre acadêmico. A experiência dessa metodologia é relatada nesse trabalho como fonte de auxílio para outros professores que passam por situações e anseios semelhantes. As conclusões principais obtidas neste trabalho são a possibilidade da (tão desejada) prática da interdisciplinaridade aliada à percepção do aluno e ao reconhecimento das empresas do potencial dos alunos de graduação do curso de engenharia de produção.
\end{abstract}

Palavras-chave: Interdisciplinaridade, ensino, Preactor.

\section{Introdução}

Na região da Grande Vitória, composta pelos municípios de Vitória, Vila Velha, Serra, Cariacica e Viana, no estado do Espírito Santo está localizado um parque industrial de grande importância. Grandes empresas nacionais, como a Companhia Siderúrgica de Tubarão (CST), a Companhia Vale do Rio Doce (CVRD) e a Companhia Belgo Mineira, e micro indústrias locais tem proporcionado um laboratório muito ativo para aplicação prática dos conceitos de engenharia de produção ensinados na teoria em sala de aula.

Os alunos do $7^{\circ}$ período curso de Engenharia de Produção da UVV ao cursarem as disciplinas Processos Industriais, Planejamento de Instalações, Organização e Avaliação do Trabalho e Gerência e Controle de Qualidade, são orientados a desenvolverem, em equipe, um 
trabalho prático sobre a programação da produção de uma linha de produtos real utilizando o software Preactor adquirido pela instituição em 2000. Este trabalho prático pode ser efetuado em qualquer ramo de atividade, desde os ramos tradicionais da indústria como também no setor de serviços e comércio. Normalmente as equipes optam pelas empresas onde algum aluno já esteja empregado ou em fase de estágio.

As equipes são formadas por afinidade entre os membros não podendo ultrapassar a quantidade de três alunos por grupo. A linha de produção é sugerida pelos grupos e aprovada pelo professor orientador com base na complexidade do processo e tempo disponível para o fechamento do trabalho. Os trabalhos na sua maioria são executados em indústrias.

Embora o mercado capixaba ainda forme poucos engenheiros de produção e, conseqüentemente, a profissão não esteja tão difundida como nos outros estados da região sudeste, os alunos costumam a entrar em estágios supervisionados muito cedo, em geral no $5^{\circ}$ período. Ao entrar nas empresas como estagiários, os alunos começam a visualizar situações onde melhorias podem ser feitas, mas que, para serem implementadas, necessitam de uma ferramenta que auxilie a decisão, onde por muitas vezes serão necessárias decisões baseadas nas teorias de múltiplas disciplinas.

Diante das percepções da coordenação de curso em contato com alunos, professores e gerentes, buscou-se uma ferramenta que permitisse a interdisciplinaridade na prática. Em parceria com a empresa Tecmaran o software Preactor foi o escolhido para o projeto.

O projeto teve início em Fevereiro de 2004 e até o momento já foram concluídos 21 trabalhos e outros 13 estão em desenvolvimento.

\section{Referencial Teórico}

Hoje, vivemos uma realidade onde, na medida em que os processos mercantis e produtivos tornam-se mais complexos e dinâmicos, o trabalho deve interligar-se à aprendizagem, para que as organizações permaneçam competitivas (SENGE, 2004). Se por um lado, esse fato deixa clara a necessidade de permanente reciclagem dos profissionais das organizações, torna extremamente obscura a tarefa do desenvolvimento dos futuros profissionais, aqueles que ainda se encontra nos bancos das universidades.

A Engenharia de Produção aborda aspectos relacionados à gestão do negócio, gestão da produção e sistemas técnicos, estando os extremos "linkados" às ciências sociais (administração de empresas) e ciências naturais (engenharias tradicionais) (CUNHA, 2002). Nesse sentido, durante a fase de obtenção formal do conhecimento, o aluno do curso de graduação em engenharia de produção depara-se com uma gama diversa de disciplinas, que abrangem conceitos organizacionais 
fundamentais, conceitos operacionais e conceitos gerenciais. Tais conceitos seguem, por necessidade pedagógica e mesmo operacional, um determinado fluxo, que não necessariamente formará no treinando a idéia geral adequada do que é a Organização.

Para Chrispim e Werneck (2003), no processo de ensino-aprendizagem é necessário cada vez mais colocar as informações de uma forma mais flexível e uso generalizado, além disso, os conteúdos das informações devem permitir assimilação rápida e eficiente. Tais necessidades têm atraído a atenção de especialistas em educação na reestruturação e modernização dos cursos, adequando-os às novas metodologias e consolidando outras já existentes, visando à formação de profissionais habilitados a enfrentar os desafios decorrentes dos avanços tecnológicos, bem como propiciar condições e meios com vistas a uma educação

Conceição e Gonçalves (2004) afirmam que atualmente, um dos grandes desafios encontrados pelos profissionais da educação é aliar a tecnologia computacional com o ensino em si, de forma que se utilize essa tecnologia com o objetivo de melhorar o processo ensinoaprendizagem. O computador pode representar uma transformação no modo de pensar e de educar. Salienta-se que o uso do computador no processo ensino-aprendizagem pode ser analisado em dois aspectos: educar para uma sociedade informatizada ou utilizar a informática para educar. Isso implica em uma alteração de postura dos profissionais em geral e, portanto, requer o repensar de alguns processos educacionais.

Nesse contexto, as tecnologias da informação e da comunicação estão sendo cada vez mais empregadas na educação, viabilizando processos educacionais mais interativos. A utilização dessas tecnologias possibilita a criação de um caminho alternativo que liga o aprendiz ao conhecimento, favorecendo o desenvolvimento de novos métodos e práticas no processo de ensino/aprendizagem. Essas tecnologias estão mudando o ensino e a pesquisa (LANGLOIS, 1998).

Nessa linha, a simulação empresarial e a metodologia vivencial destacam-se como técnicas complementares às aulas expositivas tradicionais (aluno, professor, quadro-negro ou transparências). A primeira por já estar sendo utilizada com sucesso há mais de 30 anos, nas mais diversas áreas de ensino, na busca do aperfeiçoamento didático (KNABBEN e FERRARI, 1995) e a segunda por abordar a dinâmica dos alunos e estreitar relacionamentos, estimulando a prédisposição ao risco e a ousadia num ambiente lúdico (GRAMIGNA, 2004). O processo criativo do grupo é ampliado e soluções para problemas antes considerados sem solução surgem com mais facilidade.

Ainda segundo Gramigna (2004), o grande diferencial na estratégia vivencial é que todas as melhorias são propostas pelo próprio grupo a partir da análise conclusiva de resultados. Outro ponto de destaque é o desenvolvimento de recursos humanos, uma vez que as correntes administrativas surgidas desde o movimento da escola das relações humanas relacionam melhorias ou mudanças 
nos processos produtivos/tecnológicos com desenvolvimento dos recursos humanos (LOPES e WILHELM, 1996). Desse modo, atividades que compreendessem fatores como relacionamento interpessoal, criatividade, poder de decisão, rápida aplicação (tempo disponível em uma aula) e baixo custo de desenvolvimento e aplicação, seriam eficientes para o processo de fixação dos conceitos. No contexto da engenharia de produção, estudos de caso reais com a orientação de professores atendem satisfatoriamente esses quesitos.

\section{Metodologia}

A metodologia para o projeto foi desenvolvida em conjunto com os professores do curso e os consultores técnicos da Tecmaran. Os conceitos essenciais das disciplinas foram trabalhados com os professores eas interfaces foram identificadas. Posteriormente, os professores conheceram o software e propuseram a estruturação do trabalho baseado na sequencia do cadastramento das informações no Preactor. Todos os professores participaram da elaboração da proposta do projeto, porém somente duas professoras participam diretamente das orientações em parceria com o consultor da Tecmaran.

O trabalho foi então subdividido em duas partes: $1^{\mathrm{a}}$ ) Planejamento do processo produtivo e $2^{\mathrm{a}}$ ) Análise do planejamento proposto. Essas 2 etapas foram então divididas para serem desempenhadas no $1^{\circ}$ e $2^{\circ}$ bimestre de aula. A seguir são detalhadas cada etapa do trabalho.

\section{Primeira Etapa: Planejamento do processo de produção}

Para a elaboração da primeira etapa os seguintes passos precisam ser desenvolvidos para que as informações possam ser cadastradas no software:

a) Definir ambiente de analise e definição de solução

Definir de forma clara e objetiva qual será o setor da empresa que a modelagem irá abranger.

b) Relacionar os Recursos Primários (máquinas, equipamentos, etc.)

Recursos Produtivos: Lista dos Recursos Produtivos principais a serem programados

Grupo de Recursos: Use as colunas para agrupar recursos com características semelhantes

\section{c) Relacionar os Principais Produtos}

Descrever o processo produtivo de alguns produtos característicos indicando as informações necessárias.

Produto/Família: Indicar o nome e código do produto. Caso seja possível dividir seus produtos em grupos indicar também a qual família este produto pertence. Isso pode ser útil para criar matrizes de setup.

Parte: Caso o produto apresente diferentes partes, especificá-las de modo a organizar o cadastro de operações. 
Operação/Fase: Indicar as operações envolvidas para fabricação do produto, definindo a seqüência de execução. Para isso, usar como padrão a numeração 10, 20, 30.

Recursos: Identificar quais máquinas (recursos) podem ser utilizados para execução da operação.

Tempo de Setup: Indicar o tempo de setup médio para o início de uma operação. Caso sua empresa possua setup variável dependendo da seqüência de produção utilize um formulário específico.

Tempo de Fabricação: Informe a taxa de produção utilizada para execução das operações, indicando qual a unidade de medida utilizada.

Observações: Indique alguma especificação relacionada à operação. Por exemplo, se determinada operação possui tempo de espera em relação a anterior, ou alguma característica especial.

\section{d) Relacionar os Recursos Secundários}

Recursos Secundários: Informe todos os recursos acessórios ao recurso principal Quantidade Disponível: Informe a quantidade disponível.

Uso da Restrição: Indique como é utilizado cada recurso secundário.

\section{e) Relacionar Tempos de setup dependente da seqüência (Matriz de Setup)}

Em alguns processos produtivos o tempo de setup pode variar em função da seqüência das operações ou de produtos. Para resolver isso, o Preactor precisa ser informado dos tempos de setup na forma de uma matriz "De / Para".

\section{f) Relacionar Padrão de Turno}

Indicar os horários de funcionamento da empresa, especificando os horários de paradas para almoço, lanches, etc. se houver. Informe, ainda, casos de setores que trabalhem em regimes especiais (2 ou mais turnos, sem paradas, etc.)

\section{g) Relacionar Ordens de Produção}

Indicar alguns exemplos de Ordens de Produção usuais. Informar número da ordem, produto e quantidade. Pelo menos uma Ordem para cada produto.

\section{h) Outras Informações Relevantes}

Quais outras informações relevantes para especificação de uma solução de programação e gerenciamento da produção para sua empresa? É muito importante definir quais são as principais expectativas em relação ao resultado que a modelagem deve apresentar.

\section{Segunda Etapa: Análise do Planejamento Proposto}


Após a inserção dos dados no Preactor pode-se analisar a programação para frente e para trás no subprocesso. As linhas de produção do processo podem ser simuladas. Com a inserção das ordens obtém-se a visualização através do gráfico de Gantt do seqüenciamento das mesmas.

As datas de entrega dos produtos podem ser acompanhadas ao longo do tempo e as possíveis alterações de programação podem ser facilmente gerenciadas. A alocação dos recursos em função da disponibilidade dos mesmos pode ser analisada e identificada pelos gráficos de barra.

Em alguns casos, normalmente complexos para fins de graduação, a programação da produção apresenta algumas limitações, as quais podem ser resolvidas com a inserção de regras avançadas no Preactor.

\section{Os Casos Estudados}

As empresas envolvidas no projeto de interdisciplinaridade estão localizadas na região da Grande Vitória, ES. A escolha e os contatos partiram da iniciativa de alunos que já trabalham nessas empresas ou são estagiários ou ainda que possuam algum relacionamento com os sócios. Os dados numéricos foram omitidos por motivos de segurança, mas os ganhos quantitativos são apresentados. Por questões de acesso, alguns casos tiveram mais de uma linha de produção analisada, como foi o caso da Coca-Cola, porém por questões de sigilo de dados não serão descritos. A seguir são apresentados os casos que tiveram as maiores repercussões tanto na empresa quanto em sala de aula.

\subsection{O Caso LOGASA}

Atualmente o Grupo Roca, líder mundial em produtos para banheiros, tem 42 fábricas em 17 países. O grupo incorpora as conhecidas empresas de peças hidro-sanitárias como a Incepa, Celite e Logasa. Essa última está localizada no município da Serra, ES com seu quadro efetivo de 530 funcionários, produção mensal de aproximadamente 225.000 mil peças/mês entre vasos, lavatório, cubas, colunas, caixas e acessórios para banheiros. O produto estudado será o Lavatório Suspenso da linha Guarapari 27037, conhecido popularmente como "Pia".

Durante a etapa de programação foram incluidas duas Ordens de produção, uma para o Lavatório 1 - cor branca, e outra para o lavatório 2 - cor bege, simulando pedidos reais de produção. Posteriormente foram sequenciadas as Odens de produção Para frente, e os resultados obtidos podem ser vistos nas Figuras 1 e 2. 


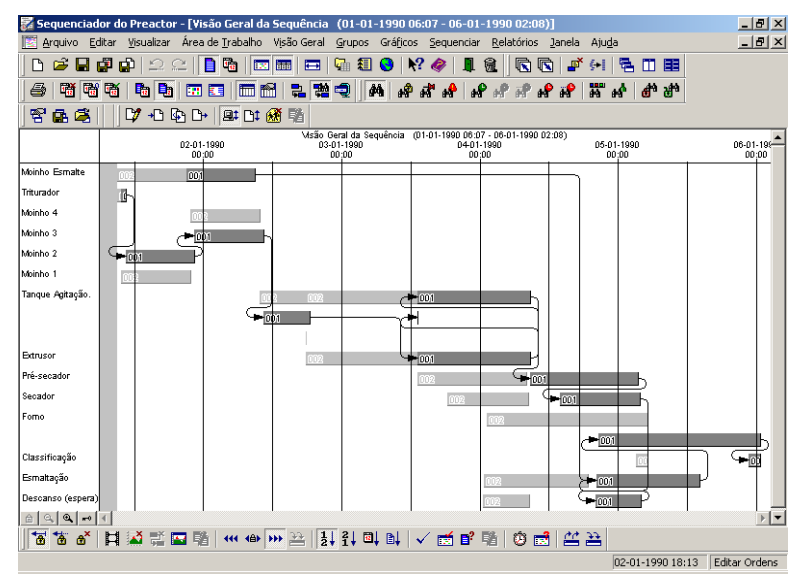

Figura 1 - Gráfico de Gantt com o sequenciamento do Lavatório 1 - cor branca

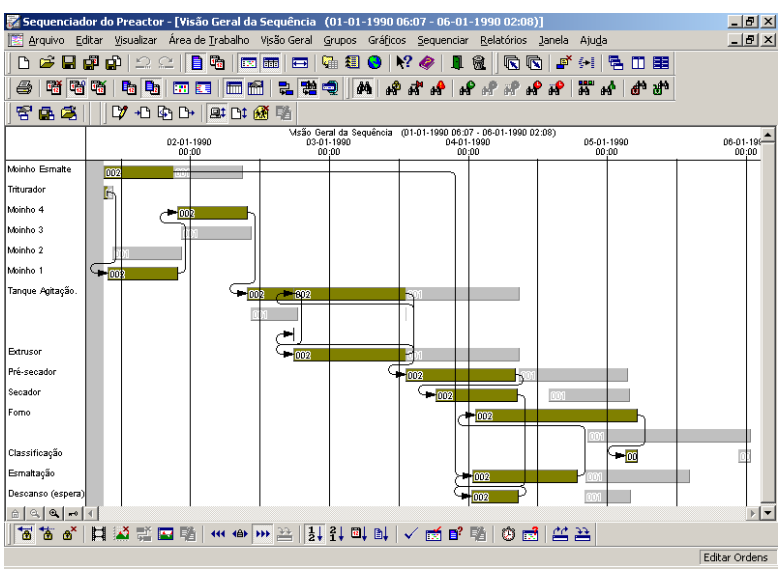

Figura 2 - Gráfico de Gantt com o sequenciamento do Lavatório 2 - cor bege

Com a modelagem do processo, verificou-se que o forno é recurso com maior taxa de utilização, informação essa que a empresa não tinha conhecimento Preactor mostrou grandes benefícios para a toda a empresa, desde a programação da produção, passando pela área de suprimentos, até a área de financeira.

\subsection{O Caso da CVRD}

O trabalho apresenta uma análise da programação do processo de moagem da pelotização da Companhia Vale do Rio Doce. Na primeira etapa do projeto foram identificadas as restrições de recursos, grupo de recursos, produto e turno de trabalho. Na segunda fase do trabalho puderam-se associar as restrições aos recursos. Houve necessidade de delimitação do modelo, pois para representação real da taxa de retorno existente no moinho seria necessário um detalhamento das restrições através de regras que não eram o objeto final do trabalho. Os resultados obtidos são apresentados em formas de gráficos e depois analisados individualmente e em conjunto.

\subsection{O processo de conversão de veículos a gás natural - GNV}

O processo produtivo consiste na instalação e manutenção de Kit gás GNV aos veículos de clientes que almejam reduzir seus custos com combustíveis tradicionais, ou seja, originalmente projetados para uso de combustíveis líquidos como o álcool, a gasolina e o diesel. Para utilizar o GNV necessitam receber acessórios (kit de conversão) que são agregados aos equipamentos originais do veiculo, tornando-o bi-combustível.

As programações geradas automaticamente pelo software Preactor foram confiáveis ao serem respeitadas as disponibilidades dos recursos, a existência de restrições e critérios de atendimento. 
A figura 3 apresenta o planejamento da seqüência de programação para trás por data final. Observa-se que no gráfico da programação não existe nenhuma ordem com destaque na cor vermelha, ou seja, o Preactor realizou o seqüenciamento de maneira que não ocorra nenhum atraso em relação às datas finais cadastradas nas ordens. Como conseqüência, algumas operações não foram alocadas.A figura mostra as 18 operações não alocadas. Haveria então a necessidade de mais recursos para a realização dessas ordens de forma a obedecer à data final exigida. Com base nas informações dever-se-ia disponibilizar outros recursos para efetuá-las em paralelo com as já alocadas.

Todas as ordens foram alocadas todas em verde

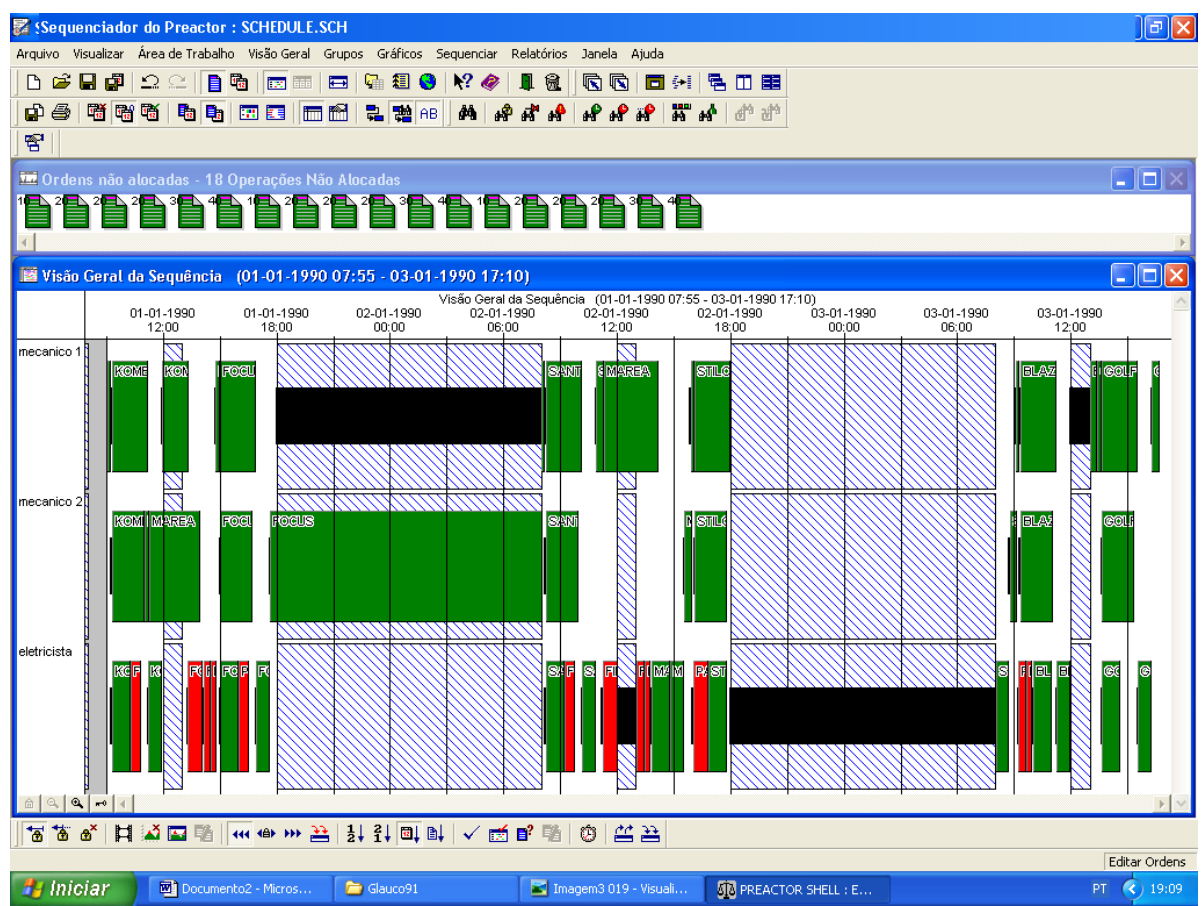

Figura 3 - Programação do seqüenciamento do processo de conversão de GNV

Analisando e comparando cada ordem de acordo com as maneiras geradas, observa-se que algumas não sofrem alteração na data e horário de finalização, e outras sofrem pequenas alterações no horário, obedecendo à data final cadastrada para a ordem. Porém foram destacadas algumas que sofrem influência da maneira como são programadas, como é o caso das ordens Fiesta, Santana e Stilo. Quando a programação é feita por prioridade à ordem Stilo permanece de acordo, mas as ordens Santana e Fiesta ficam destacadas em vermelho mostrando que estas não estão obedecendo à data final. Ao optar por data final o quadro se reverte e a ordem Stilo passa a não obedecer à data. Desta maneira torna-se mais fácil a identificação das ordens que deixaram de obedecer a programação e a opção pela maneira mais adequada a realidade da empresa.

\subsection{O Caso Embali Indústrias Plásticas Ltda}


Indústria fundada em 1995, com fabricação destinada aos frascos de chup-chup e que, com o passar do tempo, foi conquistando e ganhando espaço no mercado de embalagens. Localizada em Cariacica, ES, hoje possui mais de 150 funcionários, com frota própria para entrega em todo o país. A Embali possui em seu complexo 19 máquinas sopradoras e 2 máquinas injetoras que periodicamente passam por inspeção e manutenção.

As garrafas de plástico são fabricadas mediante um processo contínuo de sopro por extrusão. A maioria é produzida com material reciclável aprovado pela FDA, tendo alta resistência ao impacto e sólidas propriedades de proteção. As garrafas de HDPE superam o padrão da indústria por sua qualidade e durabilidade.

As garrafas fabricadas com polietileno apresentam grande variedade de tamanhos e formatos, e servem para alimentos, bebidas, incluindo também os recipientes para produtos de higiene pessoal e limpeza doméstica, recipientes para químicos industriais, depósitos para gasolina e outras substâncias inflamáveis e garrafas leves.

Apesar da pouca complexidade dos processos da empresa pesquisada, o trabalho desenvolvido foi de grande importância para os alunos e, principalmente, para os empresários. Os resultados sustentaram os argumentos de capacidade de produção ociosa e a conseqüente expansão para MG e para o nordeste. Para os alunos contribuiu para o desenvolvimento da visão crítica e da capacidade analítica com o foco em processos, competências fundamentais para um Engenheiro de Produção.

\section{Conclusão}

Como pôde ser observada, a metodologia utilizada pelo curso de Engenharia de Produção da UVV para se praticar a interdisciplinaridade aliada à vivência do aluno em dados reais pode ser considerada um sucesso. Foram apresentados somente alguns dos casos já concluídos.

Poucos foram os casos que foram abortados pelo professor, e quando aconteceram foram no período embrionário. As razões foram de complexidade do processo escolhido pelos grupos e não de falta de acesso aos dados. Acredita-se que a escolha da empresa por parte do grupo contribua bastante para o baixo resultado de trabalhos abortados. Nos casos onde houve necessidade de se interromper um estudo, os alunos foram orientados pelo professor a escolher entre as alternativas de 1) Reduzir a complexidade do processo ou 2) Escolher novo processo a ser estudado.

Ressaltamos que o software empregado, o Preactor na versão acadêmica, se mostrou uma ferramenta surpreendente, no tocante ao uso e também aos seus recursos visuais, lógicos e estatísticos.

A proximidade física e a parceria com a empresa Tecmaran permitiram o desenvolvimento de professores e o esclarecimento de dúvidas dos alunos. 


\section{Referências}

CHRISPIM, E.M. e WERNECK, R.F. Contexto e prática em Engenharia de Produção: Estudo de caso de uma organização como fonte de conhecimento. In: Encontro Nacional de Engenharia de Produção, Ouro Preto. Anais do XXIII Encontro Nacional de Engenharia de Produção. Ouro, 2003.

CONCEIÇÃO K. e GONÇALVES, M. Contribuição para o ensino de Matemática nos cursos de Engenharia. Anais do XXIV Encontro Nacional de Engenharia de Produção. Florianópolis, 2004.

CUNHA, G.D. Um panorama atual da Engenharia de Produção. In: ABEPRO - ASSOCIAÇÃO BRASILEIRA DE ENGENHARIA DE PRODUÇÃO. Porto Alegre. Disponível em <http://www.abepro.org.br>. Acesso em: 15 out., 2003.

GRAMIGNA, M. R. M. Jogo de Empresa - Desenvolvimento e Identificação de Competências. [on line: http://www.rh.com.br/ler.php?cod=3369\&org=6; capturado em 10/02/2004].

KNABBEN, B. C.; FERRARI, R. A A simulação estratégica no processo de ensino/aprendizagem - os jogos de empresa. 8p. Artigo do VI ENAGRAD - Encontro nacional dos Cursos de Graduação em Administração, 1995.

LANGLOIS, T. Universities and new information and communication technologies: issues and strategies. European Journal of Engineering Education, v.23, n.3, p285-295, 1996.

cross ${ }^{\text {ref }}$

LOPES, M. C.; WILHELM, P. P. H. Um modelo de treinamento de liderança através de técnicas de simulação empresarial. 1996. Revista de Negócios. Vol.2. Número 1, 1996.

SENGE, P.M. A quinta disciplina. $16^{\text {a }}$ edição. Editora Best Seller, 1994.

TECMARAN Apostila FCS Avançado, 2004.

\section{Dados dos autores:}

Nome completo: Patrícia Alcântara Cardoso

Filiação institucional: Pontifícia Universidade Católica do Paraná

Departamento: Engenharia de Produção e Sistemas

Função ou cargo ocupado: Professora Adjunto

Endereço: R. Imaculada Conceição, 1155

Parque Tecnológico - Bloco III - $2^{\circ}$ Andar

Prado Velho - Curitiba - PR - CEP: 80.215-901

www.ppgeps.pucpr.br

Telefones para contato: (41)3271-2404/2579

e-mail: patricia.alcantara@pucpr.br

\section{Recebido para publicação em: 18/01/2007 \\ Aceito para publicação em: 10/03/2007}

